\title{
ANALISIS PERLAKUAN AKUNTANSI ASET TETAP BERDASARKAN SAK-ETAP NO. 15 PADA KOPERASI PT. PISMA PUTRA TEXTILE PEKALONGAN
}

\author{
Rizka Ariyanti*, Sri Murniati \\ Dosen Prodi Akuntansi Politeknik Pusmanu \\ Korespondensi: rizkaariyanti81@gmail.com
}

\begin{abstract}
Assets still have sufficient material value in the financial statements and are an important part in supporting cooperative operations. Therefore cooperatives need to implement fixed asset accounting policies in accordance with the Entity Financial Accounting Standards without Public Accountability (SAK-ETAP) No.15. This study aims to obtain empirical evidence and analyze the accounting treatment of fixed assets applied to the cooperatives of PT. Pisma Putra Textile. The research method used is descriptive method with a qualitative approach and data collection techniques by means of field studies and literature. The types of data used in the study are primary data and secondary data. After an analysis of the results of interviews and searches for documents related to the classification of fixed assets, the recognition and presentation of assets can still be known that the cooperative PT. Pisma Putra Textile has not applied the treatment of its fixed assets in accordance with the Entity Financial Accounting Standards without Public Accountability (SAK-ETAP) No.15.
\end{abstract}

Keywords: Classification of fixed assets, Recognition, Presentation, SAK-ETAP No.15.

\section{PENDAHULUAN}

Secara umum tujuan utama didirikannya perusahaan adalah untuk memperoleh laba yang optimal atas investasi yang telah ditanamkan dan dapat mempertahankan kelancaran usaha dalam jangka waktu yang panjang. Salah satu investasi tersebut adalah aset tetap yang digunakan dalam kegiatan normal perusahaan yaitu aset yang mempunyai umur ekonomis lebih dari satu tahun. Untuk mencapainya diperlukan pengelolaan yang efektif dalam penggunaan, pemeliharaan maupun pencatatan akuntansinya. Menurut Suharli (2006: 259) menyatakan aset tetap adalah harta berwujud (tangible asset) yang memiliki masa manfaat ekonomis lebih dari satu tahun bernilai material, dan digunakan untuk kegiatan operasi normal perusahaan dan merupakan pengeluaran yang nilainya besar. Aset tetap berwujud pada dasarnya bisa memberikan gambaran kapitalisasi yang wajar, oleh karena itu dibutuhkan adanya perlakuan akuntansi yang memadai mulai dari saat perolehan sampai dengan saat pengalokasian biaya selama umur aset tetap berwujud tersebut. Perlakuan aset tetap berwujud ini bertujuan untuk memberikan kelayakan penyajian. Aset tetap dibedakan menjadi dua, yaitu aset tetap berwujud dan aset tetap tidak berwujud. Aset tetap berwujud yang dimiliki untuk digunakan dalam produksi atau penyediaan barang atau jasa, untuk disewakan ke pihak lain, atau untuk tujuan administratif dan diharapkan akan digunakan lebih dari satu periode. Koperasi dalam menyusun laporan keuangan harus benar-benar disesuaikan dengan standar besar kecilnya jumlah aset di neraca yang dapat mempengaruhi kewajaran laporan keuangan dan selanjutnya akan mempengaruhi para pemakai laporan keuangan dalam mengambil keputusan. Oleh karena itu, untuk memperoleh kewajaran dalam penyajian jumlah aset tetap dalam laporan keuangan, perusahaan perlu menerapkan kebijakan akuntansi aset tetap berpedoman pada prinsip akuntansi yang berlaku, yaitu Standar Akuntansi Keuangan Entitas Tanpa Akuntanbilitas Publik No.15 2009 tentang aset tetap. 


\section{RUMUSAN MASALAH}

Rumusan masalah dalam penelitian ini yaitu bagaimana perlakuan akuntansi aset tetap berdasarkan SAK ETAP NO 15 pada koperasi Putra Mandiri PT. Pisma Putra Textile?

\section{TINJAUAN PUSTAKA}

\subsection{Standar Akuntansi Keuangan Entitas Tanpa Akuntabilitas Publik (SAK ETAP)}

Secara umum Standar Akuntansi Keuangan merupakan pedoman pokok penyusunan dan penyajian laporan keuangan bagi perusahaan, koperasi dan unit ekonomi lain yang sangat penting agar laporan keuangan lebih berguna, dapat dimengerti, dibandingkan dan tidak menyesatkan. Terdapat empatalasan penting dalam Standar Akuntansi Keuangan yaitu :

1. Memberi pedoman dan peraturan bagi akuntan publik agar dapat melaksanakan tugas dengan independen, hati-hati dan dapat mengabdikan keahliannya dan kejujuran meliputi penyusunan laporan keuangan.

2. Dapat menyajikan informasi tentang posisi keuangan, kegiatan dan prestasi perusahaan. Informasi yang disusun berdasarkan Standar Akuntansi Keuangan yang diharapkan mempunyai sifat jelas, konsisten, terpercaya dan dapat diperbandingkan

3. Dapat menarik perhatian para ahli dan praktisi dibidang teori dan Standar Akuntansi. Semakin banyak Standar Akuntansi yang yang dikeluarkan semakin banyak kontroversi dan semakin banyak usaha untuk berdebat, berpolemik dan melakukan penelitian.

4. Memberikan database kepada pemerintah tentang berbagai informasi yang dianggap penting dalam perhitungan pajak, peraturan tentang perusahaan, perencanaan, pengaturan ekonomi, peningkatan efisiensi ekonomi dan tujuan makro lainnya.

\subsection{Aset Tetap}

Aset tetap merupakan harta kekayaan perusahaan / koperasi yang dimiliki perusahaan digunakan untuk menjalankan operasionalnya sehingga dengan menggunakan asset tetap kinerja Aktiva atau aset adalah segala sumber daya dan harta yang dimiliki perusahaan untuk digunakan dalam operasionalnya sehingga dengan menggunakan asset tetap kinerja perusahaan akan maksimal dan akan mendapatkan laba yang optimal

\subsection{Perlakuan Akuntansi Aset Tetap Pada Koperasi Putra PT. Pisma PutraTextile}

Menurut Ikatan Akuntan Indonesia (2013:ETAP.49), perlakuan akuntansi atas aset tetap meliputi:

\subsubsection{Pengakuan}

Pengakuan aset tetap sebagaimana untuk aset lainnya, dalam SAK ETAP menyatakan bahwa entitas harus mengakui biaya perolehan aset tetap sebagai aset tetap jika:

a. kemungkinan bahwa manfaat ekonomi yang terkait dengan pos tersebut akan mengalir dari atau ke dalam entitas, dan

b. pos tersebut mempunyai nilai atau biaya yang dapat diukur dengan andal 


\subsubsection{Biaya Perolehan Aset Tetap}

Berdasarkan SAK ETAP (2009:15.7) Biaya perolehan meliputi:

a. Harga beli, termasuk biaya hukum dan broker, bea impor dan pajak pembelian yang tidak boleh dikreditkan, setelah dikurangi diskon pembelian dan potongan lainnya.

b. Biaya-biaya yang dapat distribusikan lansung untuk membawa aset ke lokasi dan kondisi maksud menajemen. Biaya-biaya ini termasuk biaya penyiapan lahan untuk pabrik, biaya penanganan dan penyerahan awal, biaya instalasi dan perakitan, dan biaya pengujian fungsionalitas

c. Estimasi awal biaya pembongkaran aset, biaya pemindahan aset dan biaya restorasi lokasi.

\subsubsection{Perolehan Aset tetap}

Aset tetap dapat diperoleh dengan berbagai cara, dimana masingmasing cara perolehan akan mempengaruhi penentuan harga perolehan. Caracara tersebut adalah dengan pembelian tunai, pembelian angsuran, ditukar dengan aset tetap lainnya, ditukar dengan surat-surat berharga, diperoleh dari hadiah/donasi dan aset yang dibuat sendiri. Adapun cara perolehan aset tetap menurut Baridwan (2004:278) adalah sebagai berikut :

a. Pembelian Tunai

b. Pembelian Gabungan / Lumpsum

c. Pembelian dengan angsuran

d. Ditukar dengan asset lain

e. Hadiah atau donasi

f. Aset yang dibuat sendiri

3.3.4. Penyusutan atau Depresiasi

Menurut Baridwan (2008:306) pengertian Akuntansi depresiasi adalah : "Suatu sistem akuntansi yang bertujuan untuk membagikan harga perolehan atau nilai dasar lain dari aset tetap berwujud, dikurangi nilai sisa (jika ada), selama umur kegunaan unit itu yang ditaksir (mungkin berupa suatu kumpulan aset-aset) dalam suatu cara yang sistematis dan rasional"

3.3.5. Penyajian asset dalam laporan keuangan

SAK ETAP menyebutkan bahwa laporan keuangan menyajikan posisi keuangan, kinerja keuangan, dan arus kas suatu entitas secara wajar dan harus membuat suatu pernyataan eksplisit dan secarapenuh atas kepatuhan tersebut dalam catatan atas laporan keuangan Pengurus koperasi menyusun laporan tahunan yang memuat sekurang kurangnya :

a. Neraca

b. Perhitungan Hasil Usaha

c. Catatan Atas Laporan Keuangan

d. Laporan Perubahan Ekuitas

e. Laporan Arus Kas

Koperasi PT. Pisma Putra Textile adalah koperasi yang bergerak dalam bidang jasa transportasi, simpan pinjam anggota, perdagangan dan sewa kendaraan. Fenomena yang terjadi pada koperasi PT. Pisma Putra Textile menyangkut asset tetap berwujudnya, yaitu dalam pencatatan asset tetap berwujud koperasi tidak melakukan pemisahan, sehingga 
asset tetap yang dilaporkan oleh koperasi sebesar harga perolehannya saja. Penilaian harga perolehan asset tetap tidak disertai dengan biaya-biaya lainnya sampai asset tetap tersebut siap dipergunakan dalam kegiatan operasional koperasi.Dalam SAK-ETAP perlakuan akuntansi asset tetap berwujud yang diperoleh koperasi seharusnya dicatat secara terpisah, meskipun asset tersebut diperoleh secara bersamaan.

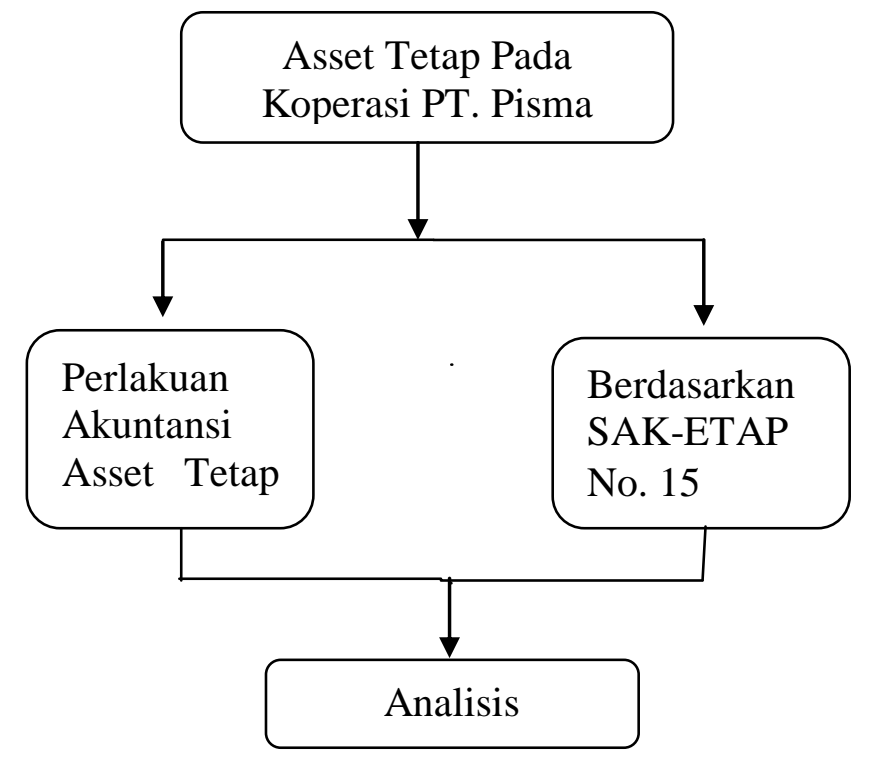

Gambar 1 Kerangka Pemikiran

\section{METODE}

Metode analisis data yang penulis gunakan adalah analisis deskriptif dengan pendekatan kualitatif yaitu metode yang bertujuan untuk menggambarkan keadaan koperasi berdasarkan kenyataan yang sesungguhnya terjadi di koperasi PT. Pisma Putra Textile dengan tujuan untuk mengetahui perlakuan akuntansi aset tetap yang diterapkan terhadap kesesuaiannya dengan standard SAKETAP

\section{HASIL DAN PEMBAHASAN}

\subsection{Klasifikasi AsetTetap}

Sebagai koperasi karyawan, koperasi Putra Mandiri memiliki aset tetap dalam jumlah yang memadai dan terdiri dari berbagai jenis sehingga perlu dilakukan pengelompokkan lebih lanjut atas aset tetap tersebut. Berdasarkan hasil pengumpulan data/informasi yang dilakukan oleh penulis, dapat diketahui bahwa pembagian atau pengklasifikasian aset tetap yang dimiliki koperasi PT. Pisma Putra Textile dibandingkan dengan SAK-ETAP No. 15 dapat dilihat pada tabel dibawah ini :

Tabel 1 Perbandingan Klasifikasi Aset Tetap

\begin{tabular}{|c|c|c|}
\hline $\begin{array}{c}\text { Koperasi PT. Pisma Putra } \\
\text { Textile }\end{array}$ & SAK-ETAP No. 15 & Kesesuaian \\
\hline Kendaraan & Kendaraan & Sesuai \\
\hline Kantor Koperasi & Bangunan & Sesuai \\
\hline Inventaris Koperasi & Perlengkapan & Tidak sesuai \\
Perlengkapan & & Sesuai \\
\hline
\end{tabular}

Sumber : Data Primer Olahan 2017

Inventaris koperasi tidak dikelompokkan sebagai akun perlengkapan, hal tersebut tidak sesuai dengan Standar Akuntansi Keuangan. Namun berdasarkan hasil penelitian yang dilakukan, hal tersebut terjadi karena menurut koperasi PT. Pisma 
Putra Textile benda berwujud yang digolongkan sebagai inventaris koperasi tidak sama dengan perlengkapan karena aset tetap perlengkapan yang dimaksud disini adalah perlengkapan yang digunakan untuk perdagangan. Inventaris koperasi digolongkan sebagai segala bentuk benda berwujud yang terdapat pada kantor koperasi baik menggunakan tenaga listrik untuk menghidupkannya (komputer) maupun tidak (meja kursi tamu).

\subsection{Pengakuan Aset Tetap}

Berdasarkan hasil pengumpulan data/informasi yang dilakukan penulis pada koperasi PT. Pisma Putra Textile untuk perlakuan aset tetapnya diketahui bahwa pengakuan aset tetap terjadi jika kemungkinan besar aset yang dimiliki memberikan manfaat ekonomi bagi entitas, maksudnya kepemilikan aset tetap memberikan manfaat ekonomi untuk menunjang kegiatan operasional koperasi sehingga dapat memperoleh keuntungan dari penggunaan asset tetap tersebut. Selain itu, aset tetap diakui ketika diperkirakan mempunyai masa manfaat lebih dari satu tahun dan tidak dimaksudkan untuk dijual.

Biaya perolehan setiap aset tetap koperasi PT. Pisma Putra Textile dapat diukur secara andal yaitu dengan menjumlahkan harga perolehan dan seluruh biaya yang terjadi hingga aset tetap tersebut siap untuk digunakan dan karena ada dokumen atau catatan pendukung atas perolehan aset tetap tersebut.

Berdasarkan hasil penelitian perbandingan pengakuan aset tetap pada koperasi PT. Pisma Putra Textile dengan SAK-ETAP No. 15, dapat dinyatakan sebagai berikut :

Tabel 2 Perbandingan Pengakuan Aset Tetap

\begin{tabular}{|l|l|c|}
\hline \multicolumn{1}{|c|}{ Koperasi PT. Pisma Putra Textile } & SAK-ETAP No. 15 & Kesesuaian \\
\hline Koperasi PT Pisma Putra Textile mengakui aset & Kemungkinan besar & Sesuai \\
yang dimiliki dengan ketentuan aset yang dimiliki & entitas akan & \\
atau yang diperoleh adalah aset yang memiliki & memperoleh manfaat & \\
masa manfaat dan memberikan manfaat ekonomis & ekonomik masa & \\
lebih dari satu periode dan mampu mendukung & depan dari aset & \\
kegiatan operasional koperasi. & tersebut. & \\
\hline $\begin{array}{l}\text { Biaya perolehan aset tetap yang dimiliki koperasi } \\
\text { PT. Pisma Putra Textile dapat diukur secara andal }\end{array}$ & $\begin{array}{l}\text { Biaya perolehan aset } \\
\text { tetap dapat diukur }\end{array}$ & Sesuai \\
karena ada dokumentasi atau catatan pendukung & secara andal. & \\
atas perolehan aset tetap. & & \\
Sumber: Data Primer Olahan 2017. & & \\
\hline
\end{tabular}

Berdasarkan tabel diatas dapat dilihat perbandingan antara ketentuan SAKETAP No. 15 dan penerapan akuntansi terhadap aset tetap yang diterapkan pada koperasi PT. Pisma Putra Textile. Sesuai dengan hasil penelitian yang ada, perlakuan akuntansi untuk pengakuan aset tetap yang diterapkan koperasi PT. Pisma Putra Textile sesuai dengan ketentuan SAK-ETAP No.15.

\subsection{Penyajian Aset Tetap dalam Laporan Keuangan}

5.3.1. Penyajian AsetTetap dalam Laporan Laba/rugi

Berdasarkan hasil pengumpulan data/informasi yang dilakukan penulis dapat diketahui bahwa setiap aset tetap yang dimiliki koperasi PT. Pisma 
Putra Textile disajikan dalam neraca secara terpisah.Nilai aset tetap yang disajikan pada neraca merupakan nilai bersih atas aset tetap tersebut pada tahun pelaporan.

Berikut penyajian aset tetap koperasi PT. Pisma Putra Textile dalam laporan Laba/Rugi tahun 2016/2017

Tabel 3 Laporan Laba/Rugi

\begin{tabular}{|c|c|c|}
\hline No & Keterangan & Tahun 2017 \\
\hline & & ( $\mathbf{R p})$ \\
\hline A. & \multicolumn{2}{|c|}{ Pendapatan / Penjualan Barang \& Jasa } \\
\hline 1. & Unit toko waserda \& perdagangan & $306.075 .830,00$ \\
\hline 2. & Unit jasa transportasi / angkutan & $432.645 .627,00$ \\
\hline 3. & Unit jasa piutang anggota & $637.528 .543,00$ \\
\hline 4. & Unit jasa sewa kendaraan & $10.500 .000,00$ \\
\hline \multirow[t]{2}{*}{5.} & Pendapatan diluar usaha & $14.277 .768,54$ \\
\hline & Total pendapatan & 1.401.027.768,54 \\
\hline B. & \multicolumn{2}{|l|}{ Beban Usaha } \\
\hline 1. & B. tenaga kerja & 214.044.962,00 \\
\hline 2. & B. honor pengurus & $129.200 .000,00$ \\
\hline 3. & B. pengobatan karyawan & $861.000,00$ \\
\hline 4. & B. THR \& bingkisan hari raya & $275.000 .000,00$ \\
\hline 5. & B. ATK & $466.500,00$ \\
\hline 6. & B. rapat / jamuan tamu & $2197.900,00$ \\
\hline 7. & B. cetak \& foto kopi & $110.300,00$ \\
\hline 8. & B. operasional angkutan & $100.436 .426,95$ \\
\hline 9. & B. pajak penghasilan & $37.205 .750,00$ \\
\hline 10. & B. perijinan & $2.5000 .000,00$ \\
\hline 11. & B. Administrasi Bank & $474.099,54$ \\
\hline 12. & B. bunga Bank & $169.825 .505,64$ \\
\hline 13. & B. R A T & $46.000 .000,00$ \\
\hline 14. & B. sumbangan pihak luar & $750.000,00$ \\
\hline 15. & B. Jamsostek & $10.415 .408,00$ \\
\hline 16. & B. depresiasi / penyusutan & $47.969 .530,14$ \\
\hline \multirow[t]{4}{*}{17.} & B. operasional waserda & 3.932 .600 \\
\hline & Total Biaya Usaha & $1.041 .389 .982,27$ \\
\hline & \multicolumn{2}{|l|}{ Total $\mathrm{A}-$ Total $\mathrm{B}=$} \\
\hline & Total Laba bersih & 359.637 .786 \\
\hline
\end{tabular}

Sumber : Data Primer Olahan 2017

5.3.2. Penyajian Aset Tetap dalamLaporan Posisi Keuangan

Tabel 4 Laporan Posisi Keuangan

\begin{tabular}{|l|r|r|}
\hline \multicolumn{3}{|c|}{ ASSET } \\
\hline \multicolumn{1}{|c|}{ Aset Lancar : } & \multicolumn{1}{c|}{ 31 Des. ' 17} & \multicolumn{1}{c|}{ 31 Des. ' 16} \\
\hline Kas & $55.980 .653,36$ & $35.652 .486,29$ \\
\hline Bank & $127.903 .328,46$ & $42.246 .739,17$ \\
\hline Piutang dagang & $336.520 .800,00$ & $392.405 .700,00$ \\
\hline Piutang usaha & $1.590 .226 .013,52$ & $2.532 .660 .524,97$ \\
\hline Total Asset Lancar & $2.224 .922 .185,34$ & $3.154 .869 .972,43$ \\
\hline
\end{tabular}




\begin{tabular}{|c|c|c|}
\hline \multicolumn{3}{|c|}{ ASSET } \\
\hline Aset Lancar : & 31 Des. ' 17 & 31 Des. ' 16 \\
\hline \multicolumn{3}{|l|}{ Aset Tetap : } \\
\hline Perlengkapan & $12.729 .150,00$ & $12.729 .150,00$ \\
\hline Kendaraan & $1.415 .241 .444,14$ & $1.415 .241 .444,14$ \\
\hline Inventaris & $35.188 .400,00$ & $35.188 .400,00$ \\
\hline Total Harga Perolehan & $1.463 .158 .994,14$ & $1.463 .158 .994,14$ \\
\hline Akumulasi penyusutan & $(1.294 .650 .748,20)$ & $\begin{array}{r}(1.246 .681 .218,0 \\
6)\end{array}$ \\
\hline Nilai buku asset tetap & $168.508 .245,94$ & $216.477 .776,08$ \\
\hline Total Aset & 2.393.430.431,28 & 3.371.347.748,51 \\
\hline \multicolumn{3}{|c|}{ LIABILITIES } \\
\hline $\begin{array}{l}\text { Hutang Jangka } \\
\text { Pendek }\end{array}$ & 31 Des. ' 17 & 31 Des. ' 16 \\
\hline Hutang dagang & $2.425 .700,00$ & $9.102 .600,00$ \\
\hline Hutang SHU & $49.010 .912,56$ & $56.982 .617,49$ \\
\hline \multicolumn{3}{|l|}{ Hutang Jk. Panjang : } \\
\hline Leasing & $54.042 .744,00$ & $59.222 .156,00$ \\
\hline KMK Bank Jateng & $710.128 .822,00$ & $1.592 .280 .316,00$ \\
\hline KMK Muamalat & - & $187.552 .448,00$ \\
\hline Total Hutang Jk. Pjg & $764.171 .566,00$ & $1.839 .054 .920,00$ \\
\hline \multicolumn{3}{|l|}{ Ekuitas : } \\
\hline Simpanan pokok & $6.410 .000,00$ & $6.930 .000,00$ \\
\hline Simpanan wajib & $711.052 .582,53$ & $634.132 .582,53$ \\
\hline Simpanan hari raya & $155.896 .000,00$ & $153.355 .300,00$ \\
\hline Donasi & $237.286 .080,00$ & $237.286 .080,00$ \\
\hline Laba/ Rugi & $434.503 .648,47$ & $387.881 .506,89$ \\
\hline Laba/Rugi th berjalan & $1.577 .822 .252,71$ & 1.466.207.611,00 \\
\hline Total Liabi & $2.393 .430 .431,27$ & 3.371.347.748,50 \\
\hline
\end{tabular}

Sumber : Data Primer Olahan 2017

Berdasarkan hasil penelitian perbandingan penyajian aset tetap pada koperasi PT. Pisma Putra Textile dengan SAK-ETAP No. 15, dapat dinyatakan sebagai berikut :

Tabel 5 Perbandingan Penyajian Aset Tetap

\begin{tabular}{|l|l|l|l|}
\hline Keterangan & Koperasi PT. Pisma Putra Textile & \multicolumn{1}{|c|}{$\begin{array}{c}\text { SAK-ETAP No. } \\
\text { 15 }\end{array}$} & Kesesuaian \\
\hline Penyajian & $\begin{array}{l}\text { telah berupaya menyajikan laporan } \\
\text { keuangan secara wajar, jujur } \\
\text { berdasarkan transaksi, dan diukur } \\
\text { menurut kriteria pengakuan yang } \\
\text { sudah ditetapkan }\end{array}$ & & \\
\end{tabular}




\begin{tabular}{|c|c|c|c|}
\hline Keterangan & Koperasi PT. Pisma Putra Textile & $\begin{array}{l}\text { SAK-ETAP No. } \\
15\end{array}$ & Kesesuaian \\
\hline \multicolumn{4}{|l|}{ Penyajian } \\
\hline & Belum menerapkan SAK ETAP & $\begin{array}{l}\text { Kepatuhan } \\
\text { terhadap SAK- } \\
\text { ETAP }\end{array}$ & Tidak sesuai \\
\hline & $\begin{array}{l}\text { Sudah menyajikan analisis tingkat } \\
\text { kesehatan (likuiditas, solvabilitas }\end{array}$ & $\begin{array}{l}\text { Kelangsungan } \\
\text { usaha }\end{array}$ & Sesuai \\
\hline & $\begin{array}{l}\text { Rutin mengeluarkan laporan keuangan } \\
\text { tahunan yang terintegral dalam } \\
\text { laporan Rapat Anggota Tahunan }\end{array}$ & $\begin{array}{l}\text { Frekuensi } \\
\text { pelaporan }\end{array}$ & Sesuai \\
\hline & $\begin{array}{l}\text { Pos-pos yang disajikan oleh } \\
\text { Koperasi PT Pismatex tahun 2016- } \\
2017 \text { konsisten }\end{array}$ & $\begin{array}{l}\text { Penyajian yang } \\
\text { konsisten }\end{array}$ & Sesuai \\
\hline & $\begin{array}{l}\text { Menyajikan secara komparatif untuk } \\
\text { laporan laba/rugi dan laporan posisi } \\
\text { keuangan }\end{array}$ & $\begin{array}{l}\text { Informasi } \\
\text { komparatif }\end{array}$ & Sesuai \\
\hline & $\begin{array}{l}\text { Belum memisahkan materialitas dan } \\
\text { agregasi }\end{array}$ & $\begin{array}{l}\text { Matrealitas dan } \\
\text { agregasi }\end{array}$ & Tidak sesuai \\
\hline
\end{tabular}

Sumber : Data Primer Olahan 2017.

\section{SIMPULAN DAN SARAN}

\subsection{Simpulan}

Koperasi sebagai badan hukum wajib patuh terhadap ketentuan dan peraturan/perundang-undangan yang berlaku. Sebagai entitas yang tidak memiliki akuntabilitas publik disyaratkan dalam Peraturan Menteri Keuangan dan Usaha Kecil Menengah no. 12 tahun 2015 bahwa penyusunan laporan keuangan harusberdasarkann SAK-ETAP.

Hasil analisis dari Koperasi Karyawan PT. Pisma Putra Textile belum sepenuhnya menerapkan pengakuan, pencatatan dan penyajian aset tetap koperasi sesuai standar akuntasi yang berlaku, mengenai perlakuan akuntansi asset tetap dan penyajian laporan keuangan berdasarkan SAK ETAP dapat disimpulkan bahwa dalam perlakuan akuntansi asset tetap dan cara penyajian laporan keuangannya masih terdapat beberapa ketidak sesuaian dengan kaidah perlakuan akuntansi asset tetap dan penyajian laporan keuangan menurut SAKETAP.

Adapun hal-hal yang membuat koperasi ini memiliki kekurangan dalam menyajikan laporan keuangannya berdasarkan SAK ETAP adalah karena minimnya pengetahuan mengenai SAK ETAP itu sendiri dan kurangnya kesadaran manajemen akan pentingnya laporan keuangan.

\subsection{Saran}

Koperasi PT. Pisma Putra Textile sebaiknya melakukan pengakuan, pencatatan dan pelaporan aset tetapnya sesuai dengan SAK ETAP No. 15 yang berlaku untuk dimasa selanjutnya agar tidak terjadi kelebihan atau kekurangan penyajian dalam nilai beban penyusutan, akumulasi dan nilai buku aset tetap perusahaan sehingga informasi yang diterima perusahaan atas laporan keuangan akan lebih akurat dan akuntabel 


\section{DAFTAR PUSTAKA}

Baridwan Zaki, 2004. “Intermediate Accounting” Edisi kedelapan Yogyakarta, BPFE

Ikatan Akuntan Indonesia ( IAI) 2009 Standar Keuangan Entitas Tanpa Akuntanbilitas Publik (SAK ETAP) Jakarta

Pangerapan, O.R. 2013, Analisis Perlakuan Akuntansi Untuk Website Pada PT. Bank Sulut (Persero) Manado, Jurnal EMBA Universitas Sam Ratulangi Manado. http://www.ejournalunsrat.ac.id diakses 7 Februari 2016, Vol. 1, No. 3.Hal.761-770.

Rudianto. 2008. Pengantar Akuntansi :Erlangga. Jakarta.

Smith, Jay M, dan K. Fred Skousen, 2005. Akuntansi Intermediate, diterjemah oleh Alfonsus Sirait, S.E, Cetakan Kelima, Jilid 1, Edisi ke Sembilan, Penerbit Erlangga, Jakarta.

Soemarso. 2005. Akuntansi Suatu Pengantar. Edisi Revisi, Jakarta: Salemba.

Suharli,Michell. 2006. Akuntansi untuk Bisnis Jasa dan Dagang. Edisi Pertama. Penerbit Graha Ilmu: Yogyakarta 